\title{
Tamanho de amostra para a estimação do coeficiente de correlação linear de Pearson entre caracteres de mamoneira
}

\section{Sample size to estimate the Pearson correlation coefficient among characters of castor bean}

\author{
Alberto Cargnelutti Filho ${ }^{1 *}$; Sidinei José Lopes ${ }^{1}$; Betânia Brum²; \\ Marcos Toebe ${ }^{3}$; Tatiani Reis da Silveira ${ }^{3}$; Gabriele Casarotto ${ }^{3}$
}

\begin{abstract}
Resumo
No estudo de relações lineares é importante dimensionar adequadamente a amostra para a estimação do coeficiente de correlação linear de Pearson entre pares de caracteres, com confiabilidade aceitável. O objetivo deste trabalho foi determinar o tamanho de amostra (número de plantas) para a estimação do coeficiente de correlação linear de Pearson entre 21 caracteres de mamoneira. Foram avaliadas 41 e 55 plantas dos híbridos Sara e Lyra, respectivamente, quanto aos caracteres de semente, de plântula, de planta adulta e de produção, em Santa Maria, Estado do Rio Grande do Sul, no ano agrícola de 2007/2008. Calculou-se o tamanho de amostra por meio de reamostragem "bootstrap", para a estimação do coeficiente de correlação linear de Pearson, para as amplitudes do intervalo de confiança de "bootstrap" de $95 \%$ iguais a $0,20,0,35$ e 0,50 , para cada um dos 210 pares de caracteres. Independentemente do híbrido de mamoneira, 96 plantas são suficientes para a estimação do coeficiente de correlação linear de Pearson, para a amplitude do intervalo de confiança de "bootstrap" de $95 \%$, máxima de 0,52 .

Palavras-chave: Ricinus communis L., planejamento experimental, reamostragem "bootstrap", dimensionamento de amostra, precisão experimental
\end{abstract}

\begin{abstract}
In the study of linear relationships, it is important to define correctly the sample size, to estimate the Pearson correlation coefficient among pairs of characters, with acceptable reliability. The aim of this research was to determine the sample size (number of plants) to estimate the Pearson correlation coefficient among 21 characters of castor bean. It was evaluated 41 and 55 plants of the Sara and Lyra hybrids, respectively, regarding to the characters of seed, seedling, adult plant and yield in Santa Maria, Rio Grande do Sul State, Brazil, in the agriculture year of 2007/2008. It was calculated the sample size through bootstrap resampling, to estimate the Pearson correlation coefficient, for the amplitudes of the bootstrap confidence interval $95 \%$ equal to $0.20,0.35$ and 0.50 , for each of 210 pairs of characters. Regardless of the castor bean hybrids, 96 plants are sufficient to estimate the Pearson correlation coefficient, to the amplitude of the bootstrap confidence interval $95 \%$, maximum of the 0.52 .

Key words: Ricinus communis L., experimental planning, bootstrap resampling, sample dimensioning, experimental precision
\end{abstract}

${ }^{1}$ Engenheiros Agrônomos, Profs. Drs. do Dept ${ }^{\circ}$ de Fitotecnia/CCR, Universidade Federal de Santa Maria, UFSM, Santa Maria, RS.E-mail: cargnelutti@pq.cnpq.br; sjlopes@pq.cnpq.br

${ }^{2}$ Eng $^{\mathrm{a}} \mathrm{Agr}^{\mathrm{a}}$, Doutoranda do Programa de Pós-Graduação em Agronomia da UFSM. E-mail: bbufsm@gmail.com

3 Engenheiros Agrônomos, Discentes de Mestrado do Programa de Pós-Graduação em Agronomia da UFSM. E-mail: m.toebe@, gmail.com; tatianisilveira@yahoo.com.br; gabrielecasarotto@gmail.com

* Autor para correspondência 


\section{Introdução}

Nas Ciências Agrárias e, mais especificamente, em programas de melhoramento de plantas, o estudo de relações lineares entre os caracteres por meio do coeficiente de correlação linear de Pearson e por procedimentos complementares, tais como correlações parciais, análise de trilha e correlação canônica (CRUZ; REGAZZI, 1997; CRUZ; CARNEIRO, 2003; HAIR et al., 2005), pode fornecer resultados importantes, especialmente na identificação de caracteres para seleção indireta.

O coeficiente de correlação linear de Pearson (r) é uma estatística utilizada para medir a força, a intensidade ou o grau de relação linear entre duas variáveis aleatórias (STEVENSON, 2001; BARBETTA; REIS; BORNIA, 2004; KAZMIER, 2007; FERREIRA, 2009). O sinal do coeficiente de correlação linear de Pearson expressa o sentido da correlação e a intensidade é representada por um valor numérico que oscila entre -1 e 1 . Em situações extremas, dois caracteres podem apresentar correlação linear negativa perfeita $(r=$ -1) ou positiva perfeita $(r=1)$, ou ainda ausência de relação linear $(\mathrm{r}=0)$.

Quando o tamanho de amostra é pequeno, o valor do coeficiente de correlação linear de Pearson, para ser significativo precisa ter elevada magnitude (próximo de $|1|$ ). Neste caso, embora o valor do coeficiente apresente significância estatística, a amostra pode não ser representativa da população (STEVENSON, 2001; HAIR et al., 2005) e, consequentemente, o coeficiente também pode não representar a verdadeira relação entre os caracteres. Por outro lado, quando o tamanho de amostra for excessivamente grande, um pequeno valor do coeficiente de correlação linear de Pearson (próximo de zero) pode ser considerado significativo. Porém não necessariamente seja uma relação importante entre os caracteres do ponto de vista prático (STEVENSON, 2001; KAZMIER, 2007; HAIR et al., 2005).

Estudos do dimensionamento de amostra têm sido realizados para a estimação da média de caracteres nas culturas de milho (STORCK et al., 2007), feijão (CARGNELUTTI FILHO et al., 2008), soja (CARGNELUTTI FILHO et al., 2009) e mamona (CARGNELUTTI FILHO et al., 2010a) e, de maneira geral, têm evidenciado variabilidade do tamanho de amostra entre genótipos, caracteres e experimentos. A qualidade fisiológica de sementes de mamona (Ricinus communis L.) também tem sido estudada (MACHADO et al., 2010).

No entanto, estudos sobre o dimensionamento de amostra para a estimação do coeficiente de correlação linear de Pearson entre pares de caracteres de mamoneira (Ricinus communis L.), não foram encontrados na literatura. Assim, o objetivo deste trabalho foi determinar o tamanho de amostra (número de plantas) para a estimação do coeficiente de correlação linear de Pearson, entre 21 caracteres de híbridos de mamoneira.

\section{Material e Métodos}

Dois híbridos de mamoneira, Sara e Lyra, foram avaliados em um campo experimental de Santa Maria, Rio Grande do Sul (latitude 29 $42^{\prime}$ 'S, longitude $53^{\circ} 49^{\prime} \mathrm{W}$ e $95 \mathrm{~m}$ de altitude), no ano agrícola 2007/2008. Foram avaliadas, individualmente, 90 sementes do híbrido Sara e 90 sementes do híbrido Lyra quanto aos caracteres de semente (Tabela 1). As sementes foram identificadas com números de um a 180 e semeadas em área experimental de $15 \mathrm{~m}$ de comprimento x $16 \mathrm{~m}$ de largura, em 19 de outubro de 2007, conforme a recomendação para o cultivo de mamoneira (WREGE et al., 2007), juntamente com as demais sementes (não identificadas) que compuseram as seis parcelas (três parcelas do híbrido Sara e três parcelas do híbrido Lyra). O espaçamento foi de $0,6 \mathrm{~m}$ entre plantas e $1,2 \mathrm{~m}$ entre linhas. Entre as sementes identificadas, emergiram 41 e 55 plantas dos híbridos Sara e Lyra, respectivamente, as quais foram avaliadas individualmente quanto aos caracteres de plântula, de planta adulta e de produção (Tabela 1). 
Tabela 1. Sigla, unidade e forma de coleta de caracteres de semente, de plântula, de planta adulta e de produção de híbridos de mamoneira (Ricinus communis L).

\begin{tabular}{|c|c|c|c|}
\hline Caractere & Sigla & Unidade & Forma de coleta \\
\hline \multicolumn{4}{|c|}{---- } \\
\hline Peso & PESO & g & $\begin{array}{l}\text { Pesagem individual realizada em balança analítica de precisão de } \\
0,0001 \mathrm{~g} \text {. }\end{array}$ \\
\hline Comprimento & COMP & $\mathrm{mm}$ & $\begin{array}{l}\text { Medido com paquímetro digital da carúncula até a outra extremidade } \\
\text { da semente, no sentido da rafe. }\end{array}$ \\
\hline Largura & LARG & $\mathrm{mm}$ & $\begin{array}{l}\text { Medida com paquímetro digital na parte central da semente, } \\
\text { perpendicular à medida do comprimento. }\end{array}$ \\
\hline Área & AREA & $\mathrm{mm}^{2}$ & Comprimento $\mathrm{x}$ largura \\
\hline Espessura & ESPE & $\mathrm{mm}$ & Medida com paquímetro digital na região mediana da semente. \\
\hline \multicolumn{4}{|c|}{ 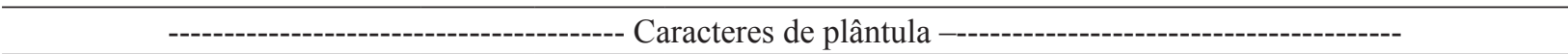 } \\
\hline $\begin{array}{l}\text { Índice SPAD aos sete dias } \\
\text { após a emergência }\end{array}$ & SP7 & - & $\begin{array}{l}\text { Medida direta com clorofilômetro. Média de três medidas realizada } \\
\text { em três pontos da plântula. }\end{array}$ \\
\hline $\begin{array}{l}\text { Índice SPAD aos } 14 \text { dias após } \\
\text { a emergência }\end{array}$ & SP14 & - & $\begin{array}{l}\text { Medida direta com clorofilômetro. Média de três medidas realizada } \\
\text { em três pontos da plântula. }\end{array}$ \\
\hline
\end{tabular}

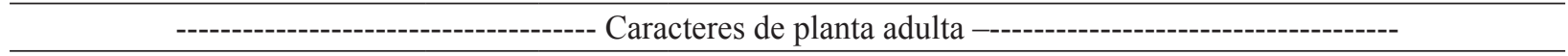

Comprimento do caule com $\quad$ CC $\quad \mathrm{cm} \quad$ No aparecimento da $1^{\mathrm{a}}$ inflorescência. Medida da distância entre

folhas verdadeiras $\quad$ a inserção da $1^{\underline{a}}$ folha verdadeira e a inserção da última folha verdadeira.

Diâmetro do caule a $10 \mathrm{~cm} \quad$ DC $\quad \mathrm{cm} \quad$ No aparecimento da $1^{\mathrm{a}}$ inflorescência, mediu-se com paquímetro do solo digital o diâmetro do caule a $10 \mathrm{~cm}$ do solo.

Área Foliar média - método $\mathrm{AF} \quad \mathrm{cm}^{2} \quad$ No aparecimento da $1^{\mathrm{a}}$ inflorescência, mediu-se o máximo comprimento e largura comprimento e largura da folha.

Altura de inserção do primeiro rácemo

APR $\quad \mathrm{cm} \quad$ No aparecimento da $1^{\mathrm{a}}$ inflorescência. Distância entre o nível do solo até o ponto de inserção do 1ํo rácemo, com régua graduada em milímetros.

Altura do rácemo mais alto $\quad \mathrm{AR} \quad \mathrm{cm} \quad$ No fim do florescimento. Distância entre o nível do solo e a extremidade do rácemo mais alto da planta.

\begin{tabular}{|c|c|c|}
\hline 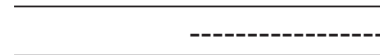 & ------- & icteres de \\
\hline $\begin{array}{l}\text { Comprimento médio dos } \\
\text { rácemos por planta }\end{array}$ & $\mathrm{CRP} \quad \mathrm{cm}$ & $\begin{array}{l}\text { Após a colheita, foi medido o comprimento do rácemo com presença } \\
\text { de cápsulas, em todos os rácemos da planta e obteve-se a média. }\end{array}$ \\
\hline
\end{tabular}

Número de rácemos por $\quad$ NRP $\quad-\quad$ Contagem realizada no momento da colheita.

planta

Número médio de cápsulas NCR por rácemo

Peso médio de cápsulas por $\quad$ PCR g rácemo

PCR g Após a colheita e retirada das cápsulas, pesaram-se as cápsulas de cada planta para obtenção da média em balança analítica de precisão de $0,0001 \mathrm{~g}$.

Peso total de cápsula por PCP g Após a colheita e retirada das cápsulas, pesaram-se todas as cápsulas planta de cada planta em balança analítica de precisão de $0,0001 \mathrm{~g}$.

continua 
continuação

$\begin{array}{lccccc}\begin{array}{l}\text { Peso médio de grãos por } \\ \text { rácemo }\end{array} & \text { PGR } & g & \begin{array}{l}\text { Após a debulha das cápsulas, os grãos de todos os rácemos da } \\ \text { planta foram pesados em balança analítica de precisão de } 0,0001 \mathrm{~g} .\end{array} \\ \begin{array}{l}\text { Produtividade de grãos por } \\ \text { planta }\end{array} & \text { PGP } & \mathrm{g} & \begin{array}{l}\text { Após a debulha das cápsulas, foi pesada a produção de grãos por } \\ \text { planta em balança analítica de precisão de } 0,0001 \mathrm{~g} .\end{array} \\ \begin{array}{l}\text { Epicarpo (casca) } \\ \text { Massa de cem grãos }\end{array} & \text { EPI } & \mathrm{g} & \begin{array}{l}\text { Obtida pela diferença entre o peso de cápsulas da planta e o peso } \\ \text { de grãos. }\end{array} \\ & \text { MCG } & \mathrm{g} & \begin{array}{l}\text { Média obtida pela pesagem de duas repetições de } 100 \text { sementes de } \\ \text { cada planta em balança analítica de precisão de } 0,0001 \mathrm{~g} \text {. Umidade } \\ \text { de } 9 \% .\end{array}\end{array}$

Fonte: Elaboração dos autores.

Inicialmente, com os dados individuais e em conjunto dos híbridos Sara e Lyra, foi investigada a linearidade entre os caracteres por meio de diagramas de dispersão (HAIR et al., 2005) e verificada a normalidade dos dados de cada caractere, por meio do teste de Kolmogorov-Smirnov (CAMPOS, 1983). Após, foram estimadas três matrizes de coeficientes de correlação linear de Pearson (r) entre os 21 caracteres avaliados. As matrizes foram obtidas a partir das 41 plantas do híbrido Sara (matriz 1), das 55 plantas do híbrido Lyra (matriz 2) e das 96 plantas dos dois híbridos (matriz 3). Afim de verificar se as inferências poderiam ser realizadas com a matriz 3 , foi estimado o coeficiente de correlação de Pearson entre cada par de matrizes (matriz 1 vs matriz 2, matriz 1 vs matriz 3 e matriz $2 v s$ matriz 3) e sua significância foi verificada pelo teste $\mathrm{t}$ de Student, a $5 \%$ de probabilidade, com n-2=208 graus de liberdade, em que n são os 210 pares de caracteres (combinação de 21 caracteres, tomados dois a dois). Quanto mais próximo de 1,0 for a estimativa obtida, maior concordância haverá entre as matrizes.

Tomando-se por base os dados da matriz formada por 96 plantas e 21 caracteres, foram definidos 691 tamanhos de amostra $(10,11,12, \ldots$, 700 plantas). Após, para cada tamanho de amostra, foram realizadas 1.000 simulações, por meio de reamostragem "bootstrap", com reposição. Para cada amostra simulada foi estimado o coeficiente de correlação linear de Pearson (r) para cada um dos 210 pares de caracteres. Assim, para cada tamanho de amostra, de cada par de caracteres, foram obtidas 1.000 estimativas de "bootstrap" de r (FERREIRA, 2009) e determinados os valores dos percentis 2,5\% e 97,5\%. Depois, calculou-se a amplitude do intervalo de confiança de "bootstrap" de 95\% pela diferença entre o percentil $97,5 \%$ e o percentil $2,5 \%$.

Para cada um dos 210 pares de caracteres, determinou-se o tamanho de amostra $(\mathrm{n}=$ número de plantas) para a estimação do coeficiente de correlação linear de Pearson (r), para as amplitudes do intervalo de confiança de "bootstrap" de 95\% iguais a 0,20, 0,35 e 0,50 . Para essas determinações, partiu-se do tamanho inicial (10 plantas), e considerou-se como tamanho de amostra (n), o número de plantas a partir do qual as amplitudes do intervalo de confiança de "bootstrap" de $95 \%$ foram menores ou iguais a 0,20 , 0,35 e 0,50 , respectivamente.

Construiu-se um diagrama de dispersão para visualizar as relações entre as 210 estimativas de $\mathrm{r}$, obtidas a partir das 96 plantas, e o tamanho de amostra (n) para as amplitudes do intervalo de confiança de "bootstrap" de 95\% iguais a 0,20, 0,35 e 0,50 . As análises estatísticas foram realizadas no programa R (R DEVELOPMENT CORE TEAM, 2011) e na planilha eletrônica Office Excel.

\section{Resultados e Discussão}

Examinando-se os diagramas de dispersão entre os 21 caracteres, feitos com as 41 plantas do híbrido Sara, as 55 plantas do híbrido Lyra e as 96 plantas dos dois híbridos, não foram constatados padrões 
não-lineares nos dados. Ainda, em apenas três casos (comprimento médio dos rácemos por planta do híbrido Sara, número de rácemos por planta do híbrido Lyra e número de rácemos por planta das 96 plantas) o teste de Kolmogorov-Smirnov (CAMPOS, 1983) revelou não ajuste à distribuição normal $(\mathrm{p} \leq 0,05)$ (cálculos não apresentados). Então, diante dessas considerações, e ainda do fato da determinação do tamanho de amostra, por meio de reamostragem "bootstrap", ser independente da distribuição de probabilidade dos dados, podese inferir que esse conjunto de dados oferece credibilidade ao estudo proposto.

De maneira geral, os coeficientes de correlação linear de Pearson para cada par de caracteres, foram similares entre os híbridos Sara e Lyra de mamoneira, o que mostra semelhança nas tendências, diferindo quanto à magnitude das associações. Sustentam essa inferência, o fato de que o coeficiente de correlação de Pearson (r) entre os pares de matrizes obtidas a partir das 41 plantas do híbrido Sara, das 55 plantas do híbrido Lyra e das 96 plantas dos dois híbridos foram significativos e de alta magnitude ( $r \geq 0,81$, $\mathrm{p} \leq 0,05)$. Portanto, a boa concordância existente entre essas matrizes possibilita que as inferências, de um modo geral, possam ser realizadas a partir das 96 plantas dos dois híbridos (Tabela 2), embora esses híbridos tenham sido considerados contrastantes quanto aos caracteres relacionados à plântula, à planta adulta e à produção (BRUM, 2009; CARGNELUTTI FILHO et al., 2010a), mas semelhantes quanto aos caracteres de semente (CARGNELUTTI FILHO et al., 2010a).

Tabela 2. Matriz de coeficientes de correlação linear de Pearson ${ }^{(1)}$ entre 21 caracteres dos híbridos Sara e Lyra de mamoneira (Ricinus communis L.), obtida a partir de 96 observações.

\begin{tabular}{lrrrrrrrrrr}
\hline Caractere $^{(2)}$ & COMP & LARG & AREA & ESPE & SP7 & SP14 & CC & DC & AF & APR \\
\hline PESO & 0,83 & 0,80 & 0,86 & 0,82 & 0,00 & 0,20 & 0,05 & 0,03 & 0,05 & 0,27 \\
COMP & & 0,78 & 0,95 & 0,79 & 0,18 & 0,36 & 0,08 & 0,12 & 0,10 & 0,27 \\
LARG & & & 0,93 & 0,85 & 0,18 & 0,31 & 0,01 & 0,08 & 0,05 & 0,19 \\
AREA & & & & 0,87 & 0,19 & 0,36 & 0,05 & 0,11 & 0,08 & 0,24 \\
ESPE & & & & & 0,13 & 0,29 & 0,07 & 0,15 & 0,07 & 0,23 \\
SP7 & & & & & & 0,61 & 0,03 & 0,29 & 0,27 & $-0,15$ \\
SP14 & & & & & & & 0,00 & 0,30 & 0,21 & $-0,04$ \\
CC & & & & & & & & 0,64 & 0,66 & 0,80 \\
DC & & & & & & & & & 0,77 & 0,37 \\
AF & & & & & & & & & & 0,43 \\
& & & & & & & & & & \\
& AR & CRP & NRP & NCR & PCR & PCP & PGR & PGP & EPI & MCG \\
PESO & 0,16 & $-0,14$ & 0,13 & $-0,13$ & $-0,02$ & 0,10 & $-0,04$ & 0,11 & 0,05 & $-0,03$ \\
COMP & 0,09 & $-0,14$ & 0,03 & $-0,05$ & 0,00 & 0,11 & $-0,04$ & 0,11 & 0,10 & 0,02 \\
LARG & 0,07 & $-0,06$ & 0,12 & $-0,07$ & 0,01 & $-0,01$ & $-0,01$ & 0,01 & $-0,05$ & 0,02 \\
AREA & 0,08 & $-0,10$ & 0,07 & $-0,06$ & 0,00 & 0,06 & $-0,03$ & 0,06 & 0,03 & 0,02 \\
ESPE & 0,10 & $-0,08$ & 0,11 & $-0,02$ & 0,04 & 0,08 & 0,04 & 0,09 & 0,05 & 0,13 \\
SP7 & $-0,24$ & 0,29 & $-0,35$ & 0,22 & $-0,02$ & $-0,15$ & 0,02 & $-0,15$ & $-0,15$ & 0,08 \\
SP14 & $-0,19$ & 0,18 & $-0,32$ & 0,18 & 0,03 & $-0,03$ & 0,06 & 0,00 & $-0,09$ & 0,15 \\
CC & 0,14 & 0,30 & $-0,18$ & 0,35 & 0,12 & 0,16 & 0,09 & 0,15 & 0,18 & 0,21 \\
DC & $-0,28$ & 0,55 & $-0,39$ & 0,62 & 0,22 & 0,04 & 0,22 & 0,02 & 0,07 & 0,39 \\
AF & $-0,20$ & 0,54 & $-0,42$ & 0,60 & 0,17 & 0,02 & 0,17 & 0,03 & 0,02 & 0,27 \\
& & & & & & & & & & \\
& AR & CRP & NRP & NCR & PCR & PCP & PGR & PGP & EPI & MCG
\end{tabular}


continuação

\begin{tabular}{|c|c|c|c|c|c|c|c|c|c|c|}
\hline APR & 0,38 & 0,00 & 0,08 & 0,07 & 0,07 & 0,16 & 0,06 & 0,16 & 0,15 & 0,04 \\
\hline AR & & $-0,37$ & 0,33 & $-0,35$ & $-0,17$ & 0,02 & $-0,20$ & 0,05 & $-0,04$ & $-0,10$ \\
\hline CRP & & & $-0,51$ & 0,80 & 0,03 & $-0,01$ & 0,03 & 0,00 & $-0,01$ & 0,14 \\
\hline NRP & & & & $-0,43$ & 0,04 & 0,10 & $-0,03$ & 0,08 & 0,12 & $-0,22$ \\
\hline NCR & & & & & 0,13 & $-0,01$ & 0,10 & $-0,01$ & $-0,01$ & 0,34 \\
\hline PCR & & & & & & 0,24 & 0,89 & 0,17 & 0,39 & 0,02 \\
\hline PCP & & & & & & & 0,00 & 0,99 & 0,94 & $-0,11$ \\
\hline PGR & & & & & & & & $-0,06$ & 0,15 & 0,05 \\
\hline PGP & & & & & & & & & 0,88 & $-0,09$ \\
\hline EPI & & & & & & & & & & $-0,14$ \\
\hline
\end{tabular}

(1) Valor superior a $|0,21|$ é significativo a $5 \%$ de probabilidade de erro, pelo teste $t$, com 94 graus de liberdade. (2) Siglas definidas na tabela 1.

Fonte: Elaboração dos autores.

Com base nas 96 plantas avaliadas, entre os 210 pares de caracteres, houve associação linear negativa em 11 pares $(r \leq-0,22, p \leq 0,05)$ e positiva em 50 pares $(r \geq 0,22, p \leq 0,05)$. Nos demais 149 pares de caracteres $(71 \%)$ não houve associação linear $(-0,20$ $\leq \mathrm{r} \leq 0,21, \mathrm{p}>0,05)$ (Tabela 2). O elevado número de plantas mensuradas (96 plantas) sugere que as estimativas de $r$ apresentam elevada precisão e, com isso, associações lineares de baixa magnitude $(r>|0,21|)$ são significantes. É importante examinar, além da significância estatística, a magnitude do $r$, que fornece uma significância prática de determinada associação linear (HAIR et al., 2005). Portanto, esses resultados revelam que é importante determinar um tamanho de amostra para a estimação do r, com uma determinada precisão e, após inferir em relação à sua significância estatística.

O tamanho de amostra (número de plantas) para a estimação do coeficiente de correlação linear de Pearson, para a amplitude do intervalo de confiança de "bootstrap" de 95\% igual a 0,20, oscilou entre 10 plantas para três pares de caracteres [comprimento da semente (COMP) e área da semente (AREA) $(\mathrm{r}=0,95)$, peso total de cápsula por planta $(\mathrm{PCP})$ e produtividade de grãos por planta (PGP) $(\mathrm{r}=$ $0,99)$ e peso total de cápsula por planta (PCP) e peso do epicarpo (EPI) $(\mathrm{r}=0,94)]$, e 661 plantas para o par largura de semente (LARG) e peso do epicarpo (EPI) $(r=-0,05)$ (Tabela 3$)$. Variabilidade de tamanho de amostra para a estimação da média entre genótipos, caracteres e experimentos, também foi constatada em milho (STORCK et al., 2007), em feijão (CARGNELUTTI FILHO et al., 2008), em soja (CARGNELUTTI FILHO et al., 2009) e em mamona (CARGNELUTTI FILHO et al., 2010a).

A média dos coeficientes de correlação linear de Pearson entre os pares de caracteres de semente (10 pares), de plântula (1 par), de planta adulta (10 pares) e de produção (36 pares) foi, respectivamente, 0,85 , $0,61,0,37$ e 0,14 , e a média do tamanho de amostra para a estimação do coeficiente de correlação linear de Pearson, para a amplitude do intervalo de confiança de "bootstrap" de 95\% igual a 0,20 foi, respectivamente, 44, 133, 198 e 300 plantas (Tabelas 2 e 3). Esses resultados revelam, de maneira geral, que para estudos de relações lineares, específicos por grupo de caracteres, o tamanho de amostra é crescente na seguinte ordem: caracteres de semente, de plântula, de planta adulta e de produção. Portanto, caracteres que permanecem por mais tempo sob atuação do ambiente, necessitam maior tamanho de amostra. Essa mesma ordem de acréscimo foi observada em relação ao tamanho de amostra para a estimação da média de 38 caracteres dos híbridos Sara e Lyra de mamoneira (CARGNELUTTI FILHO et al., 2010a).

Para os 210 pares de caracteres estudados, 661 plantas de mamoneira são suficientes para a 
estimação do coeficiente de correlação linear de Pearson, para a amplitude do intervalo de confiança de "bootstrap" de 95\% igual a 0,20 (Tabela 3). Do ponto de vista prático, a avaliação de 661 plantas é difícil, o que sugere que as estimativas de r sejam obtidas com menor número de plantas e com amplitude do intervalo de confiança de "bootstrap" de $95 \%$ superior a 0,20. Assim, menores tamanhos de amostra foram estimados com base em amplitudes do intervalo de confiança de "bootstrap" iguais a 0,35 e 0,50 (Figura 1). Não cabe aqui o julgamento do erro de estimação (amplitude do intervalo de confiança) máximo aceitável, ficando isso a critério do pesquisador que usufruir dessas informações para o seu planejamento experimental.

Tabela 3. Tamanho de amostra (número de plantas) para a estimação do coeficiente de correlação linear de Pearson (r), entre 21 caracteres dos híbridos Sara e Lyra de mamoneira (Ricinus communis L.), para a amplitude do intervalo de confiança de "bootstrap" de 95\% igual a 0,20.

\begin{tabular}{|c|c|c|c|c|c|c|c|c|c|c|}
\hline Caractere $^{(1)}$ & COMP & LARG & AREA & ESPE & SP7 & SP14 & $\mathrm{CC}$ & $\mathrm{DC}$ & $\mathrm{AF}$ & APR \\
\hline PESO & 61 & 47 & 41 & 43 & 453 & 341 & 343 & 338 & 345 & 285 \\
\hline COMP & & 61 & 10 & 64 & 344 & 302 & 353 & 302 & 291 & 334 \\
\hline LARG & & & 11 & 49 & 314 & 321 & 310 & 265 & 228 & 337 \\
\hline AREA & & & & 47 & 329 & 279 & 334 & 275 & 264 & 343 \\
\hline ESPE & & & & & 314 & 337 & 323 & 291 & 351 & 341 \\
\hline SP7 & & & & & & 133 & 234 & 246 & 322 & 231 \\
\hline SP14 & & & & & & & 261 & 308 & 273 & 285 \\
\hline $\mathrm{CC}$ & & & & & & & & 123 & 94 & 62 \\
\hline $\mathrm{DC}$ & & & & & & & & & 163 & 254 \\
\hline \multirow[t]{2}{*}{$\mathrm{AF}$} & & & & & & & & & & 179 \\
\hline & $\mathrm{AR}$ & CRP & NRP & NCR & PCR & PCP & PGR & PGP & EPI & MCG \\
\hline PESO & 349 & 328 & 297 & 331 & 359 & 390 & 312 & 343 & 437 & 323 \\
\hline COMP & 416 & 242 & 313 & 328 & 297 & 336 & 296 & 337 & 353 & 348 \\
\hline LARG & 414 & 282 & 242 & 313 & 302 & 457 & 275 & 392 & 661 & 399 \\
\hline AREA & 419 & 276 & 288 & 328 & 309 & 392 & 275 & 358 & 515 & 348 \\
\hline ESPE & 362 & 309 & 288 & 378 & 327 & 413 & 330 & 374 & 560 & 351 \\
\hline SP7 & 262 & 273 & 144 & 293 & 339 & 244 & 382 & 242 & 304 & 356 \\
\hline SP14 & 270 & 281 & 295 & 298 & 297 & 397 & 339 & 349 & 414 & 239 \\
\hline $\mathrm{CC}$ & 395 & 276 & 286 & 212 & 385 & 340 & 331 & 341 & 340 & 348 \\
\hline DC & 184 & 182 & 172 & 140 & 355 & 379 & 355 & 379 & 340 & 243 \\
\hline \multirow[t]{2}{*}{$\mathrm{AF}$} & 199 & 163 & 166 & 149 & 394 & 336 & 361 & 336 & 319 & 382 \\
\hline & $\mathrm{AR}$ & CRP & NRP & NCR & PCR & РCP & PGR & PGP & EPI & MCG \\
\hline APR & 326 & 327 & 434 & 241 & 325 & 361 & 304 & 377 & 356 & 396 \\
\hline $\mathrm{AR}$ & & 245 & 218 & 271 & 335 & 270 & 296 & 274 & 229 & 352 \\
\hline CRP & & & 153 & 52 & 364 & 295 & 391 & 287 & 310 & 346 \\
\hline NRP & & & & 129 & 273 & 587 & 308 & 560 & 570 & 311 \\
\hline NCR & & & & & 346 & 327 & 361 & 340 & 297 & 277 \\
\hline PCR & & & & & & 280 & 37 & 309 & 251 & 447 \\
\hline PCP & & & & & & & 312 & 10 & 10 & 399 \\
\hline PGR & & & & & & & & 297 & 336 & 406 \\
\hline PGP & & & & & & & & & 22 & 385 \\
\hline EPI & & & & & & & & & & 416 \\
\hline
\end{tabular}

${ }^{(1)}$ Siglas definidas na tabela 1 .

Fonte: Elaboração dos autores. 
Independentemente da amplitude do intervalo de confiança de "bootstrap" $(0,20,0,35$ ou 0,50$)$ para uma mesma precisão, há aumento do tamanho de amostra (número de plantas) com o decréscimo da magnitude da associação linear entre caracteres. Esses resultados revelam que para estudos de relações lineares entre caracteres, com base no mesmo número de observações para todos os caracteres, estimativas mais precisas do coeficiente de correlação de Pearson são obtidas para pares de caracteres com maior intensidade de associação linear e vice-versa. Portanto, esses resultados reforçam os resultados discutidos em Cargnelutti Filho et al. (2010b) de que, especialmente, para os caracteres com menor intensidade de associação linear, a insuficiência amostral associada a essa menor precisão poderia ser causa de resultados divergentes em publicações científicas.

Figura 1. Diagrama de dispersão entre as 210 estimativas do coeficiente de correlação linear de Pearson (r), obtido a partir das 96 plantas dos híbridos Sara e Lyra de mamoneira (Ricinus communis L.) e do tamanho de amostra (número de plantas), para as amplitudes do intervalo de confiança de "bootstrap" de $95 \%$ iguais a $0,20,0,35$ e 0,50 .

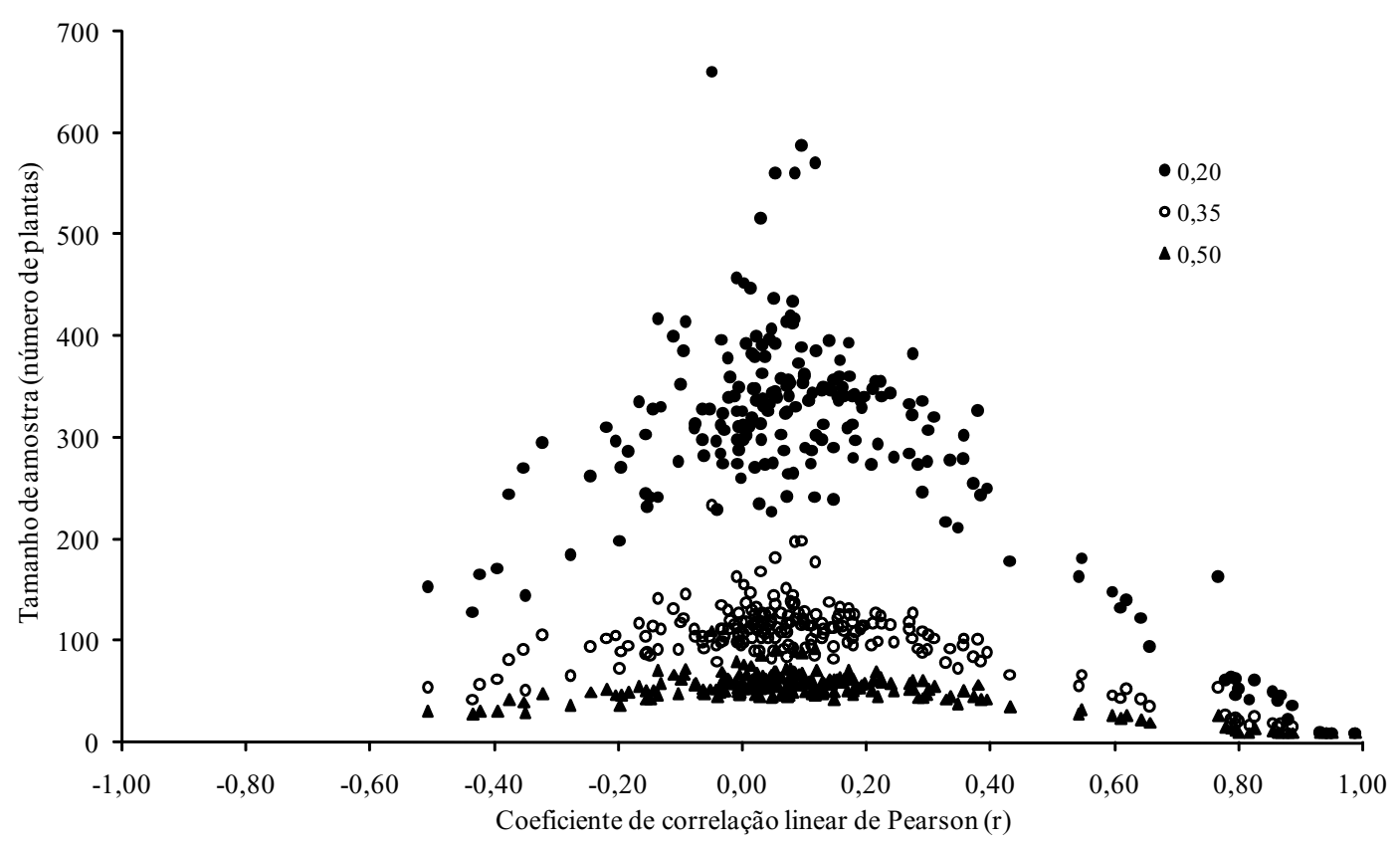

Fonte: Elaboração dos autores.

Tomando-se por base as 96 plantas avaliadas nesse estudo, a amplitude do intervalo de confiança de "bootstrap" de 95\% do coeficiente de correlação linear de Pearson oscilou entre 0,01 para o par de caracteres peso total de cápsula por planta (PCP) e produtividade de grãos por planta (PGP) $(\mathrm{r}=0,99)$ e 0,52 para o par largura de semente (LARG) e peso do epicarpo (EPI) $(\mathrm{r}=-0,05)$ (Tabela 4). Portanto, os resultados evidenciam que, do ponto de vista de técnicas experimentais, os pesquisadores da cultura de mamoneira devem considerar os caracteres, ao dimensionar o tamanho de amostra para avaliação mais precisa das relações lineares entre os mesmos. Ainda, pode-se inferir que é difícil obter estimativas do coeficiente de correlação linear de Pearson com elevada precisão, especialmente para pares de caracteres com baixa intensidade de relação linear, em função do elevado número de plantas que devem ser mensuradas. 
Tabela 4. Amplitude do intervalo de confiança de "bootstrap" de 95\% do coeficiente de correlação linear de Pearson (r), entre 21 caracteres dos híbridos Sara e Lyra de mamoneira (Ricinus communis L.), com 96 observações.

\begin{tabular}{|c|c|c|c|c|c|c|c|c|c|c|}
\hline Caractere $^{(1)}$ & COMP & LARG & AREA & ESPE & SP7 & SP14 & $\mathrm{CC}$ & $\mathrm{DC}$ & $\mathrm{AF}$ & APR \\
\hline PESO & 0,17 & 0,14 & 0,13 & 0,13 & 0,46 & 0,40 & 0,40 & 0,38 & 0,38 & 0,39 \\
\hline COMP & & 0,16 & 0,04 & 0,16 & 0,40 & 0,38 & 0,42 & 0,36 & 0,35 & 0,40 \\
\hline LARG & & & 0,05 & 0,13 & 0,38 & 0,38 & 0,38 & 0,33 & 0,33 & 0,41 \\
\hline AREA & & & & 0,13 & 0,41 & 0,36 & 0,40 & 0,35 & 0,34 & 0,40 \\
\hline ESPE & & & & & 0,37 & 0,39 & 0,42 & 0,37 & 0,40 & 0,40 \\
\hline SP7 & & & & & & 0,24 & 0,35 & 0,34 & 0,39 & 0,34 \\
\hline SP14 & & & & & & & 0,36 & 0,37 & 0,36 & 0,36 \\
\hline $\mathrm{CC}$ & & & & & & & & 0,24 & 0,20 & 0,16 \\
\hline DC & & & & & & & & & 0,26 & 0,35 \\
\hline \multirow[t]{2}{*}{$\mathrm{AF}$} & & & & & & & & & & 0,31 \\
\hline & AR & CRP & NRP & NCR & PCR & PCP & PGR & PGP & EPI & MCG \\
\hline PESO & 0,39 & 0,40 & 0,37 & 0,41 & 0,38 & 0,40 & 0,40 & 0,40 & 0,46 & 0,37 \\
\hline COMP & 0,42 & 0,35 & 0,39 & 0,39 & 0,36 & 0,38 & 0,35 & 0,38 & 0,39 & 0,40 \\
\hline LARG & 0,44 & 0,36 & 0,32 & 0,39 & 0,38 & 0,45 & 0,37 & 0,43 & 0,52 & 0,45 \\
\hline AREA & 0,43 & 0,37 & 0,35 & 0,38 & 0,36 & 0,42 & 0,36 & 0,40 & 0,47 & 0,40 \\
\hline ESPE & 0,42 & 0,39 & 0,36 & 0,43 & 0,38 & 0,41 & 0,40 & 0,40 & 0,46 & 0,38 \\
\hline SP7 & 0,36 & 0,36 & 0,26 & 0,38 & 0,40 & 0,35 & 0,39 & 0,32 & 0,38 & 0,39 \\
\hline SP14 & 0,35 & 0,35 & 0,36 & 0,38 & 0,38 & 0,43 & 0,40 & 0,40 & 0,44 & 0,33 \\
\hline $\mathrm{CC}$ & 0,44 & 0,35 & 0,35 & 0,32 & 0,45 & 0,39 & 0,40 & 0,39 & 0,42 & 0,40 \\
\hline $\mathrm{DC}$ & 0,29 & 0,28 & 0,28 & 0,25 & 0,43 & 0,41 & 0,42 & 0,40 & 0,40 & 0,34 \\
\hline \multirow[t]{2}{*}{$\mathrm{AF}$} & 0,30 & 0,26 & 0,27 & 0,26 & 0,44 & 0,38 & 0,42 & 0,39 & 0,37 & 0,42 \\
\hline & AR & CRP & NRP & NCR & PCR & РCP & PGR & PGP & EPI & MCG \\
\hline APR & 0,39 & 0,40 & 0,44 & 0,34 & 0,40 & 0,40 & 0,40 & 0,41 & 0,41 & 0,44 \\
\hline $\mathrm{AR}$ & & 0,32 & 0,31 & 0,34 & 0,39 & 0,34 & 0,36 & 0,35 & 0,33 & 0,43 \\
\hline CRP & & & 0,26 & 0,14 & 0,41 & 0,39 & 0,42 & 0,39 & 0,37 & 0,40 \\
\hline NRP & & & & 0,24 & 0,36 & 0,50 & 0,38 & 0,49 & 0,49 & 0,38 \\
\hline NCR & & & & & 0,41 & 0,38 & 0,41 & 0,39 & 0,36 & 0,36 \\
\hline PCR & & & & & & 0,36 & 0,11 & 0,37 & 0,33 & 0,46 \\
\hline PCP & & & & & & & 0,38 & 0,01 & 0,05 & 0,44 \\
\hline PGR & & & & & & & & 0,37 & 0,39 & 0,44 \\
\hline PGP & & & & & & & & & 0,09 & 0,43 \\
\hline EPI & & & & & & & & & & 0,44 \\
\hline
\end{tabular}

(1) Siglas definidas na tabela 1 .

Fonte: Elaboração dos autores.

\section{Conclusão}

Independentemente do híbrido (Sara e Lyra) de mamoneira, para os 210 pares de caracteres estudados, 96 plantas são suficientes para a estimação do coeficiente de correlação linear de Pearson, para a amplitude do intervalo de confiança de "bootstrap" de 95\%, máxima de 0,52.

\section{Agradecimentos}

Ao Conselho Nacional de Desenvolvimento Científico e Tecnológico e a Coordenação de Aperfeiçoamento de Pessoal de Nível Superior, pelas bolsas concedidas. 


\section{Referências}

BARBETTA, P. A.; REIS, M. M.; BORNIA, A. C. Estatística para cursos de engenharia e informática. São Paulo: Atlas, 2004. 410 p.

BRUM, B. Relações entre variáveis de: sementes, plântulas, plantas, produção e óleo em mamoneira. 2009. Dissertação (Mestrado em Agronomia) - Curso de Pósgraduação em Agronomia. Universidade Federal de Santa Maria, Santa Maria.

CAMPOS, H. de. Estatística experimental nãoparamétrica. 4. ed. Piracicaba: Departamento de Matemática e Estatística, ESALQ, 1983. 349 p.

CARGNELUTTI FILHO, A.; EVANGELISTA, D. H. R.; GONÇALVES, E. C. P.; STORCK, L. Tamanho de amostra de caracteres de genótipos de soja. Ciência Rural, Santa Maria, v. 39, n. 4, p. 983-991, 2009.

CARGNELUTTI FILHO, A.; LOPES, S. J.; BRUM, B.; SILVEIRA, T. R. da; TOEBE, M.; STORCK, L. Tamanho de amostra de caracteres em híbridos de mamoneira. Ciência Rural, Santa Maria, v. 40, n. 2, p. 250-257, 2010a.

CARGNELUTTI FILHO, A.; RIBEIRO, N. D.; STORCK, L.; JOST, E.; POERSCH, N. L. Tamanho de amostra de caracteres de cultivares de feijão. Ciência Rural, Santa Maria, v. 38, n. 3, p. 635-642, 2008.

CARGNELUTTI FILHO, A.; TOEBE, M.; BURIN, C.; SILVEIRA, T. R. da; CASAROTTO, G. Tamanho de amostra para estimação do coeficiente de correlação linear de Pearson entre caracteres de milho. Pesquisa Agropecuária Brasileira, Brasília, v. 45, n. 12, p. 13631371, 2010b.

CRUZ, C. D.; CARNEIRO, P. C. S. Modelos biométricos aplicados ao melhoramento genético. Viçosa: UFV, 2003. 585 p.
CRUZ, C. D.; REGAZZI, A. J. Modelos biométricos aplicados ao melhoramento genético. 2. ed. Viçosa: UFV, 1997. 390 p.

FERREIRA, D. F. Estatística básica. 2. ed. Lavras: UFLA, 2009. 664 p.

HAIR, J. F.; ANDERSON, R. E.; TATHAM, R. L.; BLACK, W. C. Análise multivariada de dados. 5. ed. Porto Alegre: Bookman, 2005. 593 p.

KAZMIER, L. J. Estatística aplicada à administração e economia. 4. ed. Porto Alegre: Bookman, 2007. 392 p.

MACHADO, C. G.; MARTINS, C. C.; CRUZ, S. C. S.; NAKAGAWA, J.; PEREIRA, F. R. S. Posição do racemo e do fruto na qualidade fisiológica de sementes de mamona durante o armazenamento. Semina: Ciências Agrárias, Londrina, v. 31, n. 2, p. 301-312, 2010.

R DEVELOPMENT CORE TEAM. $R$ : a language and environment for statistical computing. Vienna: $\mathrm{R}$ Foundation for Statistical Computing, 2011. Disponível em: <http://www.R-project.org >. Acesso em: 08 jun. 2011.

STEVENSON, W. J. Estatística aplicada à administração. São Paulo: Harbra, 2001. 495 p.

STORCK, L.; LOPES, S. J.; CARGNELUTTI FILHO, A.; MARTINI, L. F. D.; CARVALHO, M. P. de. Sample size for single, double and triple hybrid corn ear traits. Scientia Agricola, Piracicaba, v. 64, n. 1, p. 30-35, 2007.

WREGE, M. S.; SILVA, S. D. A.; STEINMETZ, S.; REISSER JUNIOR, C.; HERTER, F. G.; GARRASTAZU, M. C.; MATZENAUER, R. Zoneamento agroclimático para mamona no Rio Grande do Sul. Pelotas: Embrapa Clima Temperado, 2007. 30 p. (Embrapa Clima Temperado. Documentos, 192). 